\title{
A criança entre o falado e o escrito: a aquisição da linguagem e o uso da língua
}

\author{
Raphaela Machado Monteiro CHITTOLINA • ( \\ Universidade Federal do Rio Grande do Sul (UFRGS)
}

\section{RESUMO}

A mesa redonda aqui resenhada trata da criança e do uso da língua, mais especificamente da fala, da escrita e de suas relações na aquisição da linguagem. Cada um dos três participantes aborda esse tema com base em uma perspectiva teórica própria: uma abordagem linguística-discursiva (Lourenço Chacon), uma abordagem linguístico-enunciativa (Marlete Sandra Diedrich) e uma abordagem linguístico-funcionalista (Gabriela Maria de Oliveira-Codinhoto). Dado o percurso singular que cada participante trilha para refletir acerca do assunto, constata-se, em todas as pesquisas, um compromisso teórico e metodológico com o estudo da aquisição da linguagem. Tal compromisso se comprova no momento da análise e da

OPEN ACCESS

EDITADO POR Raquel Freitag

AVALIADO POR Giovane Fernandes Oliveira discussão dos dados, o que configura cada um dos trabalhos apresentados como uma relevante contribuição para os estudos acerca do uso da língua na constituição da criança como falante e como escrevente.

\section{ABSTRACT}

The roundtable reviewed here deals with children and the use of language, more specifically with speech, writing and their relations in language acquisition. Each of the three participants approaches this theme based on their own theoretical perspective: a linguistic-discursive approach (Lourenço Chacon), a linguistic-enunciative approach (Marlete Sandra Diedrich) and a linguistic-functionalist approach (Gabriela Maria de Oliveira-Codinhoto). Given the unique path that each participant takes to reflect on the subject, there is, in all researches, a theoretical and methodological commitment to the study of language acquisition. Such a commitment is proven at the time of data analysis and discussion, which configures each of the works 


\section{REVISTA DA ABRALIN}

presented as a relevant contribution to the studies on the use of language in the constitution of the child as a speaker and as a writer.

\section{PALAVRAS-CHAVE}

Aquisição. Fala. Escrita.

\section{KEYWORDS}

Acquisicion. Speaking. Writing.

A mesa redonda intitulada A criança e o uso da língua - fala, escrita e suas relações na aquisição da linguagem, realizada no dia 17 de julho de 2020, faz parte da programação do evento Abralin Ao Vivo - Linguists Online, da Associação Brasileira de Linguística (Abralin). Contando com uma mediação feita por Giovane Fernandes Oliveira (UFRGS), os participantes que integram a mesa são os linguistas Lourenço Chacon (Unesp), Marlete Sandra Diedrich (UPF) e Gabriela Maria de Oliveira-Codinhoto (UFAC). A partir de olhares teóricos distintos, os participantes pesquisam a fala, a escrita e as suas relações na aquisição da linguagem. Os materiais empíricos e os recortes temáticos apresentados por cada participante são distintos um do outro; entretanto, é possível percebermos um ponto convergente: trata-se do movimento investigativo a fim de compreender a constituição da criança como falante e também como escrevente em sua língua materna.

A exposição de Lourenço Chacon intitula-se A relação fala/escrita na escrita infantil. Inicialmente, Chacon apresenta dois pontos de vista para a fala e a escrita: o empírico - em que fala e escrita são fenômenos da existência humana - e o científico - em que fala e escrita são objetos de conhecimento. Enquanto objetos de conhecimento, Chacon esclarece que a fala e a escrita são conceitos construídos por diferentes perspectivas de observação científica. Assim, a perspectiva assumida por Chacon é a de que fala e escrita são dois modos de produção e de atribuição de sentido, que são construídos com base em diferentes semioses. Tais produção e atribuição de sentidos acontecem sob diferentes articulações entre a língua e as práticas discursivas; logo, a abordagem que configura toda essa reflexão é caracterizada como linguístico-discursiva. Nessa abordagem, a fala é vista como a materialidade linguística resultante de determinada prática de oralidade, enquanto prática discursiva; já a escrita é vista como a materialidade linguística resultante de determinada prática de letramento, enquanto prática discursiva também. Embora a fala resulte da oralidade, elas não são sinônimos: a oralidade é a diversidade de práticas discursivas que regulam a produção e a circulação dos aspectos linguísticos da fala, ao passo que a fala é o produto linguístico de uma prática de oralidade. Da mesma maneira, Chacon esclarece que escrita e letramento também não são sinônimos: o letramento é a diversidade de práticas discursivas que regulam a produção e a circulação dos aspectos linguísticos da escrita; já a escrita é o produto linguístico de uma prática de letramento. Portanto, os aspectos de fala/oralidade, de uma parte, e escrita/letramento, de outra parte, embora não sejam 


\section{REVISTA DA ABRALIN}

sinônimos, são planos relacionados de uma organização linguística em determinada semiose e regulados por práticas discursivas.

A partir disso, Chacon propõe que se olhe metodologicamente para essas relações entre fala e escrita por meio dedados de fala - na busca por indícios da circulação/atravessamento do sujeito não só por práticas de oralidade, como também por práticas de letramento, com base em Leda Tfouni; e igualmente por meio de dados de escrita - na busca por indícios da circulação/atravessamento do sujeito não só por práticas de letramento, mas por práticas de oralidade, com base em Manoel Corrêa. A partir desse arcabouço teórico, Chacon analisa as relações entre fala e escrita a partir de dados de escrita infantil que não atendem às convenções em relação à pontuação, à segmentação de palavras e à ortografia. Dentre esses dados, o recorte é feito por Chacon com foco na segmentação não convencional de palavras e de ortografia também não convencional. Esse não atendimento da convenção escrita, conforme a análise de Chacon expõe, pode ser visto como trânsito por práticas de oralidade e letramento e como indícios mostrados do escrevente, portanto são marcas da historicidade e da subjetividade do escrevente. Em síntese, Chacon conclui que, na aquisição da escrita, os dados analisados apontam características de enunciados falados e características de enunciados escritos; sendo assim, há uma constituição heterogênea dessas características na escrita infantil, visto que elas resultam de ajustes, na escrita, entre os trânsitos da criança por práticas de oralidade e por práticas de letramento.

Marlete Sandra Diedrich, em sua apresentação intitulada A aquisição da linguagem: uma experiência de significação, contribui com a discussão da mesa postulando uma concepção de aquisição da linguagem como uma experiência de significação. Essa proposta tem, em sua base, três pontos que guiam sua exposição: o primeiro ponto é o de que a criança fala com outros que falam; o segundo ponto é o de que a criança se constitui como falante de uma língua; o terceiro ponto é o de que a criança apreende o mundo por meio da fala. A perspectiva na qual Diedrich aborda toda essa reflexão acerca da aquisição da linguagem é a da teoria da enunciação de Émile Benveniste, a qual une homem, língua e cultura, bem como a consciência do meio social. Os princípios de linguagem, de língua, de fala e de enunciação são formulados por Diedrich da seguinte maneira: a linguagem é vista como a essência do homem; a língua é enxergada enquanto sistema de formas significantes que permite o exercício da linguagem e se atualiza no discurso; a fala é considerada a realização vocal da língua; por fim, a enunciação é o colocar a língua em funcionamento por um ato individual de utilização.

Os dados de linguagem interrogados por Diedrich envolvem dois recortes de uma criança entre um ano e um ano e meio de idade, recortes nos quais ela dialoga com uma criança mais velha, sua irmã de cinco anos de idade. Por meio das análises formuladas a partir dos dados apresentados, Diedrich se volta para os fatos de linguagem desses recortes que revelam as relações da criança com o emprego da língua e o que isso implica em sua constituição como falante. Para isso, a reflexão analítica é conduzida a partir dos três pontos anteriormente expostos, o que possibilita pensarmos no deslocamento vivenciado pela criança na linguagem. Em síntese, a conclusão de Diedrich é a de que, na relação com o outro, com uma maneira particular de estar na língua, a criança apreende o mundo e se manifesta na realização dessa língua na fala. Logo, para a pesquisadora, a aquisição da 


\section{REVISTA DA ABRALIN}

linguagem é uma experiência de significação da língua em emprego, em que a criança vivencia, de acordo com Benveniste, a função mediadora da língua que se dá entre o homem e o homem, bem como entre os homens e o mundo.

Gabriela Maria de Oliveira-Codinhoto, com sua fala intitulada As orações relativas e a aquisição da escrita: uma análise funcionalista de textos infantis, direciona a sua apresentação para uma abordagem funcionalista a fim de analisar textos infantis, produzidos por dois alunos do ensino fundamental I, de modo longitudinal, isto é, um estudo que analisa textos desses dois alunos ao longo de quatro anos do ensino fundamental I. O seu percurso analítico parte da frequência de orações relativas nesses textos para chegar a uma análise da composição textual global dos textos dos alunos. Para tanto, cabe definir o que são as orações relativas: sentenças morfossintaticamente encaixadas que atuam dentro do sintagma nominal, o qual é uma camada do nível morfossintático. Assim, as orações relativas modificam o núcleo nominal, podendo ser de dois tipos: um tipo é o das orações que adicionam informação sobre o núcleo nominal e atuam no nível interpessoal; o outro tipo é o das orações que ajudam a construir a referência do núcleo nominal e atuam no nível representacional. Embora esse seja o ponto de partida, as orações relativas não são o único aspecto trabalhado na apresentação, que conta também com outros elementos de análise, como a extensão dos textos, os tipos de oração que aparecem nesses textos, os tipos de conexão entre as partes dos textos e outras estratégias de composição textual que possam interessar à análise, tal como uma posterior comparação entre os textos. A vertente funcionalista que Oliveira-Codinhoto assume é baseada em Simon Dik, KeesHengeveld e Lachlan Mackenzie. Dessa maneira, a pesquisa aborda a noção de língua como um instrumento de interação social com propósitos comunicativos, ou seja, as estruturas linguísticas sempre são observadas a partir de seu dado real, que é o uso, e também a partir do contexto situacional imediato de interação. Já a aquisição da linguagem é vista como um desenvolvimento/aprendizagem da linguagem. Nessa direção, a escrita é entendida como um lugar de uso da língua em que o seu funcionamento é determinado por motivações linguísticas e interacionais, ao passo que a aquisição da escrita é compreendida como parte da aquisição da linguagem.

Ao longo da análise feita por Oliveira-Codinhoto, percebe-se que, da primeira série à quarta série, os textos dos dois alunos analisados modificam-se significativamente em função de enunciados que se tornam mais longos; orações que são mais desenvolvidas; conectores que são introduzidos; enfim, há, de maneira geral, uma progressão textual visível. Dito isso, Oliveira-Codinhoto conclui que, nas primeiras produções, a relação do escrevente com a interação é tão imediata que os textos, muitas vezes, não procuram situar para o leitor nem as entidades ou as personagens envolvidas nas produções nem a função do texto ou o seu enredo. Já nas produções finais, encontra-se uma preocupação maior com o contexto interacional - que altera o estatuto informacional desses textos, como também privilegia o aparecimento de estruturas linguísticas diversas e mais complexas. Por fim, trabalhos como o de Oliveira-Codinhoto contribuem, como a própria pesquisadora aponta, para o fornecimento de um arcabouço teórico capaz de estabelecer um paralelo entre a função e o uso da linguagem; para os estudos de constituintes linguísticos de domínios maiores e, finalmente, para o reforço da passagem do estatuto de dado de aquisição para dado de linguagem, o que reitera 


\section{REVISTA DA ABRALIN}

a relevância e a configuração desse dado como um lugar de testagem da teoria funcional, assim como da mudança e da variação translinguística.

Após a retomada das apresentações, embora essa mesa redonda tenha sido constituída por participantes com diferentes abordagens teóricas e metodológicas, percebe-se que as perspectivas de Chacon, Diedrich e Oliveira-Codinhoto alinham-se em alguns pontos, como os que seguem:

- A utilização da língua: nas três exposições, ainda que focalizado de modo diferente por cada uma, conforme o seu observatório teórico, todos os participantes apresentam, como ponto comum, o uso da língua.

- O compromisso investigativo com o campo da aquisição da linguagem: há uma incessante busca, visível na apresentação singular de cada participante, por uma maior compreensão acerca da constituição da criança como falante e como escrevente em sua língua materna.

- A responsabilidade teórica coma análise de dados: ainda que cada um dos participantes seja norteado por diferentes concepções linguísticas, todas as análises são ancoradas em estudos aprofundados, o que configura cada uma das apresentações como pesquisas de grandes entrelaçamentos teóricos e empíricos.

- A preocupação quanto à origem dos dados: mais uma vez,a despeito das diferenças entre as investigações apresentadas, verifica-se o rigor quanto à origem dos dados como um ponto convergente a todas. Isso porque, tanto nos corpora quanto nas análises destes, em todas as exposições, salienta-se a seriedade metodológica e analítica, bem como o tratamento ético e minucioso dos materiais empíricos.

Portanto, os participantes da mesa redonda aqui resenhada, a partir das lentes de suas respectivas teorias e análises, oferecem um esboço reflexivo do que compreendem acerca da aquisição da linguagem e, consequentemente, acerca da fala e da escrita na infância, estabelecendo diálogos com diferentes áreas da linguística, porém fortalecendo, sobretudo, a necessidade de mais pesquisas sobre um tema que já marcou, marca ou marcará parte da vida de cada um de nós: adquirir a língua por meio do uso desta.

\section{REFERÊNCIAS}

A criança e o uso da língua - fala, escrita e suas relações na aquisição da linguagem. Mesa redonda apresentada por Lourenço Chacon, Marlete Sandra Diedrich e Gabriela Maria de Oliveira-Codinhoto, 2020. 1 vídeo (2h 01min 35s). Publicado pelo canal de Associação Brasileira de Linguística. Disponível em: https://aovivo.abralin.org/lives/a-crianca-e-o-uso-da-lingua-2/. Acesso em: 21 jul. 2020. 